Journal of Education and Educational Development

7(1), 44-54, 2020.

DOI: http://dx.doi.org/10.22555/joeed.v7i1.2948

\title{
Teaching Children Road Safety Using a Simulated Environment
}

\author{
Catherine Purcell \\ PurcellC2@Cardiff.ac.uk \\ Cardiff University, United Kingdom \\ Amy R Romijn \\ Swansea University, United Kingdom \\ a.r.romijn@swansea.ac.uk
}

\begin{abstract}
The importance of road safety education is widely acknowledged; however, there is a lack of consistency in road safety interventions currently being used in UK schools. Furthermore, the majority of road safety educational programmes use knowledgebased methods, which do not necessarily translate to improved behaviour in real traffic environments. The use of virtual reality is starting to emerge as a viable option, as it allows for repeated risk-free practice. This study aimed to test the efficacy and playability of a virtual reality road crossing iPad-based game with children aged 7-9 years. A total of 137 children from primary school years 3 and 4 completed the study. The game comprised ten levels increasing in complexity. Participants navigated to a target using a magic portal into the virtual world (the iPad position matching the direction of travel). Remote, anonymous in-game data were collected and the results suggested that performance was significantly better on their final attempt as compared to their first attempt, regardless of age and gender. Overall, the results suggest that the iPad-based game allowed the children to practice road crossing in an immersive environment, without risk and could provide a useful, evidence-based addition to current road safety education in UK schools.
\end{abstract}

Keywords: gaming, primary education, road safety education, tablet technology, virtual reality 


\section{Introduction}

Globally, approximately one million people die and millions more are seriously injured on roads each year (World Health Organisation, 2015). In the UK, pedestrian casualties increased by $1 \%$ between 2016 and 2017, with $25 \%$ of these incidents involving a child aged between 0-15 years (Department for Transport, 2018 ). Given that only roughly $19 \%$ of the population fall within this age range (Office for National Statistics, 2016), children are considered a vulnerable, overrepresented group in preventable road traffic accidents. Therefore, child pedestrian safety remains a significant global health challenge and efforts to reduce the impact of child pedestrian accidents on morbidity and mortality are needed.

Previous researches have suggested that children follow a developmental trajectory that places them at risk for different pedestrian behaviours compared to adults, for example, unlike adults who have the ability to follow pedestrian signals, children may not fully understand the consequences of running between parked cars (Koopmans, Friedman, Kwon \& Sheehan, 2015). It is perhaps not surprising; therefore, that road safety education is one of the main strategies used with children to promote knowledge, improve skills and strengthen attitudes toward road crossing risk (Assailly, 2017). However, existing literature suggests a lack of consistency in the road safety interventions currently used in UK schools, and that road safety educational programmes are frequently implemented without evidence of effectiveness (Dragutinovic \& Twisk, 2006). One of the challenges for schools is that road safety education is not part of the core curriculum in primary education in the UK. Furthermore, $77 \%$ of parents believe that they are their child's primary learning source for road safety skills (Muir et al., 2017). However, in a previous study, parents were found to be inaccurate in estimating the traffic conditions under which their children would attempt to cross a road and assumed that their children would select larger inter-vehicle gaps when crossing than they do (Morrongiello \& Corbett, 2015).

Currently, widely used school interventions involve allocentric methods of teaching such as Tufty Club, which promotes the use of illustrated books for road safety education and Tales of the Road, a set of computer games using an aerial viewpoint and knowledge-based games. These allocentric methods tend to teach road safety by improving rote knowledge of safe crossing areas and other road safety rules. However, previous research has demonstrated that improving 
knowledge through allocentric methods does not necessarily translate to improved behaviour in real traffic environments (Zeedyk, Wallce, Carcary, Jones, \& Larter, 2011). Purcell and Romijn (2017) also demonstrated that allocentric methods of teaching road safety are less effective than immersive, egocentric methods for typically developing primary school aged children.

An alternative educational method is 'Kerbcraft', which is funded in areas of deprivation across the UK. This is an egocentric method of teaching road safety that involves taking children to the roadside to learn how to recognise safe and dangerous roadside locations, cross safely near to parked cars and cross safely near junctions. This type of roadside behavioural training has been found to be slightly more effective than classroom instruction (Van Scagen \& Rothengatter, 1997). On the other hand, individualised roadside pedestrian safety training programmes, such as Kerbcraft are highly time and labour intensive (Schwebel, David \& O'Neil, 2012). Kerbcraft for example, relies on the involvement of parent volunteers, making it highly resource intensive with an assumption that the programme cannot always be widely sustained in all schools.

A less time and labour intensive method of teaching road safety within schools could utilise technology to upskill children in the road crossing task. For example, research has started to demonstrate the utility of video (Arbogast et al., 2014), internet (Schwebel \& McClure 2014a) and training in a virtual reality (Schwebel, McClure, \& Severson, 2014b) to improve safe road crossing in children. Virtual reality can be defined as an immersive and interactive threedimensional computer experience occurring in real time (Rose, Attree, \& Johnson, 1996). This provides a promising strategy for the reduction of pedestrian casualties, as it allows the user to engage safely within a complex environment or undertake a task, which may otherwise be dangerous. It also allows for repeated unsupervised practice without risk of injury and automated feedback on crossing success or failure in an appealing training environment. Given that virtual reality is only a viable tool if behaviour in a virtual environment can be shown to match behaviour in the real world, Schwebel, Gaines and Severson (2008) tested the validity of using virtual reality as a tool in pedestrian road safety education. Their study involved participants (adults and children) completing simulated road crossings in both a virtual environment and an identical real environment and demonstrated that behaviour in the real and immersive environments were strongly correlated, 
indicating good construct validity.

Building on this, Purcell and Romijn (2017) attempted to ascertain whether current pedagogical approaches to teaching road safety in primary and secondary schools were appropriate in upskilling children in pedestrian road safety using a virtual reality task. Children (aged 6-12 years) completed a series of computerbased virtual reality tasks, where they were required to navigate an avatar to safely cross in different road scenarios. The child's viewpoint was manipulated to mirror the traditional pedagogical approaches taken to road safety education, using an allocentric (aerial) and egocentric (first-person) viewpoint. The results of the study highlighted the value of a first-person, realistic virtual environment (egocentric) over a less immersive aerial viewpoint task, which mirrors the current allocentric methods used in many UK schools. Children statistically preferred and were more accurate on the egocentric virtual reality task. The study suggested that a realistic egocentric educational game-based virtual reality road crossing program could be a valuable tool in teaching children how to cross the road whilst remaining safely in the classroom and could be used as a cost effective alternative to Kerbcraft, where limited resources mean that Kerbcraft may not be a viable option. The authors concluded that development and testing of such a programme was warranted given the existing evidence.

One such programme has been piloted recently by Morrongiello, Corbett, Beer and Koutsoulianos (2018). The authors tested two versions of an educational virtual reality road crossing game (how and where to cross) on virtual reality headsets and found that children who played the educational games made 7598\% fewer errors in crossing during post-test than children in the control group. Evidence is building to support the use of virtual reality in road crossing education and the current study was designed to test the efficacy and playability of a virtual road crossing iPad based game (Virtual Road World).

The aim of the study was to further increase the emerging evidence base relating to the use of immersive environments as a means of potentially reducing pedestrian casualties among children. In providing a game that is played on a tablet (rather than using virtual reality headsets), we also aimed to produce a more accessible road safety training game, which is downloadable from the Apple app store free of charge and could therefore, easily be used by children in many schools across the UK using existing IT equipment. 


\section{Methodology}

\section{Participants}

A total of 218 participants took part in this study; however, data from 81 participants were excluded from the analysis for the following reasons: no second time point data $(N=51)$; individual development plan $(N=30$; these data will be analysed separately). The mean age of participants was 8.36 years $(\mathrm{SD}=.63)$ and the gender ratio was 62:75 males to females. Participants were recruited from two school years (years 3 and 4) from four local primary schools in South Wales. The study was approved by the ethics committee at the University of South Wales.

\section{Apparatus}

The game was downloaded to school iPad Minis all running iOS 10 or above. All iPad Minis had the same dimensions (7.87 x $5.3 \times .28$ inch) and resolution of $1024 \times 768$ at 163 pixels per inch sufficient for the game. The game used a $60 \mathrm{~Hz}$ timer-loop and all simulations were created in Unreal Engine 4.19.2 from Epic Games Inc. The use of Unreal Engine enabled architectural design and vizulisation of a dynamic virtual city.

\section{Stimuli}

The game comprised ten levels, each increasing in complexity. Participants were able to view a map of the city (see Figure 1) by holding the iPad horizontally (parallel to the floor) in landscape orientation, which indicated where the participant was positioned in the virtual city and the location of their target. To navigate to the target, participants held the iPad up vertically in front of them, also in landscape orientation and could either walk or run using the green or red on-screen buttons (see Figure 2) for the child's view within the game. This game design provided children with a magic portal into the virtual world, allowing them to play the game as though they were inside the virtual world (i.e. having to physically move the iPad to look left and right before crossing). This provides a more immersive game experience and something more akin to actual road crossing practice than many other available educational road crossing games. Remote anonymous in-game data were collected on a secure server over a period of 10 months at all schools: (a) errors; (b) number of attempts; (c) level; and (d) time. In all levels, participants were presented with one or more roads to cross in order to safely reach the target. The next level could not be accessed until the participant had successfully completed the previous level. 
A successful level was defined as 70\% accuracy where 6\% was deducted for each second spent walking on the road, $8 \%$ was deducted for each second running on the road, $10 \%$ was deducted if a car was forced to stop; $0.5 \%$ was deducted for each second running on a path and $10 \%$ was deducted if a participant crossed when the traffic lights were green.

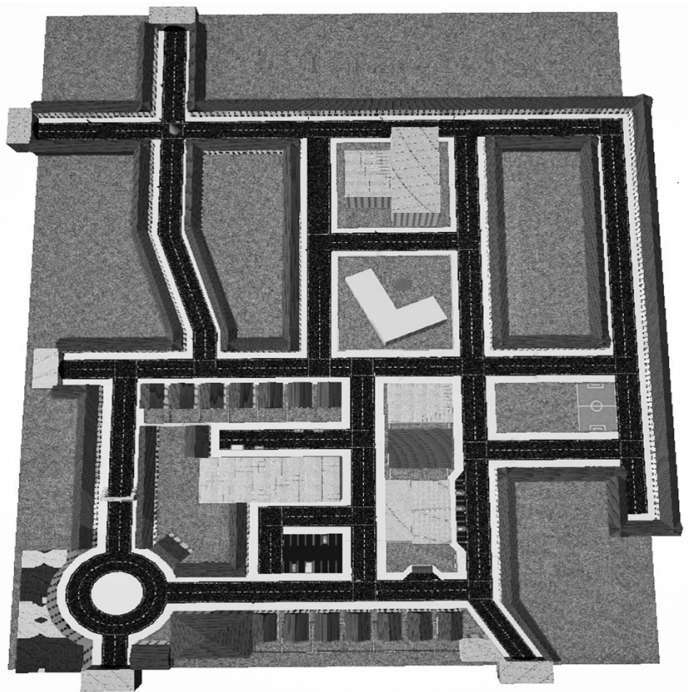

Figure 1. Screenshot of the city map, as seen by players when holding the iPad parallel to the floor.

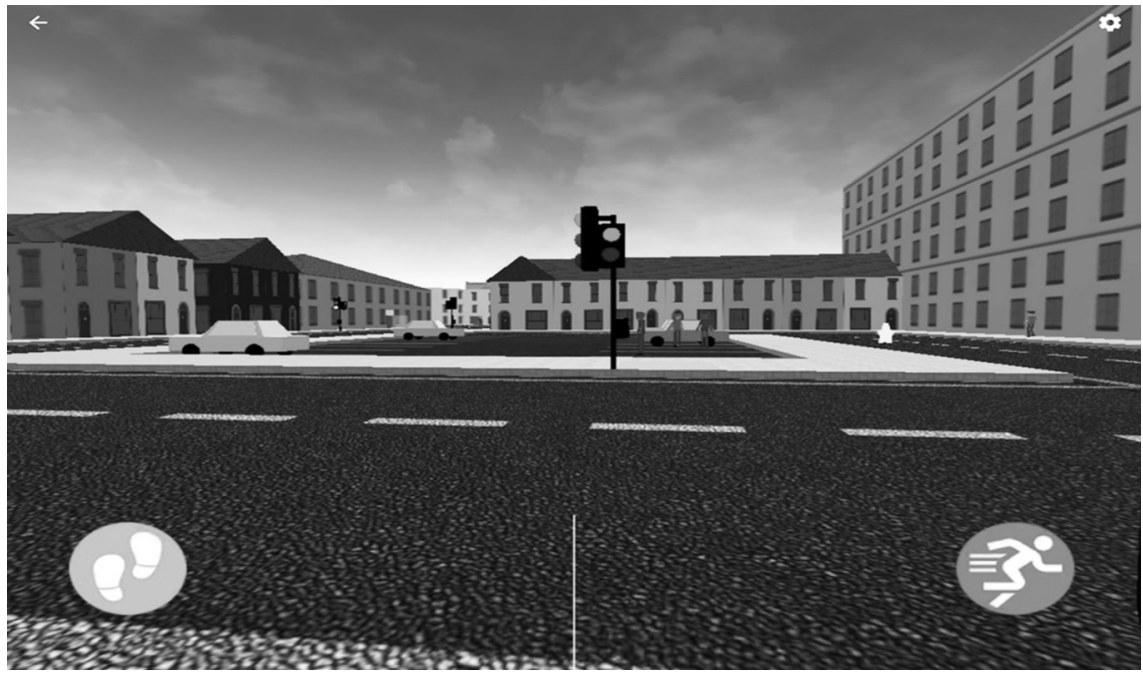

Figure 2. Screenshot of the city from the player's viewpoint, when holding the iPad up vertically in front of them. 


\section{Statistical Analysis}

Performance of each child's first and final attempt at the game was calculated using the following formula:

$\frac{\text { Time }}{\text { Errors }+1}$

A higher score indicates better performance (fewer errors made per time taken on level) with time; therefore, representing the relative difficulty/complexity of the level. A two-way mixed ANOVA was conducted to compare performance within subjects (first attempt versus final attempt), while examining whether there was any effect of gender or age $(7,8,9$ years) on performance.

\section{Findings}

Error data (count) and mean time data is shown in Table 1. In general most children made fewer than two errors in both their first and last attempt at the game. This suggests that, in general, children were using the game as it was intended, that is, they were trying to complete the simulated road crossing task as safely as possible. In addition, on average the children took longer on their final attempt compared to their first attempt, reflecting the increasing complexity of each level of the game.

Table 1

Errors (count) and Time Data for First Attempt and Final Attempt

\begin{tabular}{lll}
\hline & Attempt $\mathbf{1}$ & Final attempt \\
\hline $0-2$ errors $N(\%)$ & $118(86.13)$ & $109(79.56)$ \\
$3-5$ errors $N(\%)$ & $11(8.03)$ & $14(10.22)$ \\
$6-8$ errors $N(\%)$ & $4(2.92)$ & $7(5.11)$ \\
$8+\operatorname{errors} N(\%)$ & $4(2.92)$ & $7(5.11)$ \\
Time $\mathrm{M}(\mathrm{SD})$ & $4.13(4.06)$ & $6.71(5.05)$ \\
\hline
\end{tabular}

Table 2 shows the final level achieved by children during the game. Most children completed 5 or fewer levels of the game, which may reflect the limited time available for individual children to use shared classroom iPads during the study period. 
Table 2

Final Level Achieved by Participants

\begin{tabular}{lcc}
\hline Level & $\mathbf{N}$ & $\mathbf{\%}$ \\
\hline 2 & 21 & 15.33 \\
3 & 26 & 18.98 \\
4 & 19 & 13.87 \\
5 & 37 & 27.01 \\
6 & 12 & 8.76 \\
7 & 7 & 5.11 \\
8 & 3 & 2.19 \\
9 & 1 & 0.73 \\
10 & 11 & 8.03 \\
\hline
\end{tabular}

A two-way mixed ANOVA with Greenhouse-Geisser correction showed that the performance was significantly better on the final attempt $(\mathrm{M}=3.60, \mathrm{SD}=2.76)$ as compared to the first attempt $(\mathrm{M}=2.42, \mathrm{SD}=2.13), F(1,132)=14.50, p<.05, \eta_{p}{ }^{2}=$ .10. There was no significant effect of age or gender and no significant interaction of age and gender.

Figure 3 shows the mean performance of each age group on their first and final attempt at the game. Although the differences among age groups were not significant, 7 year old children appeared to make a slightly bigger improvement from first to last attempt as compared to both 8 and 9 year old children.

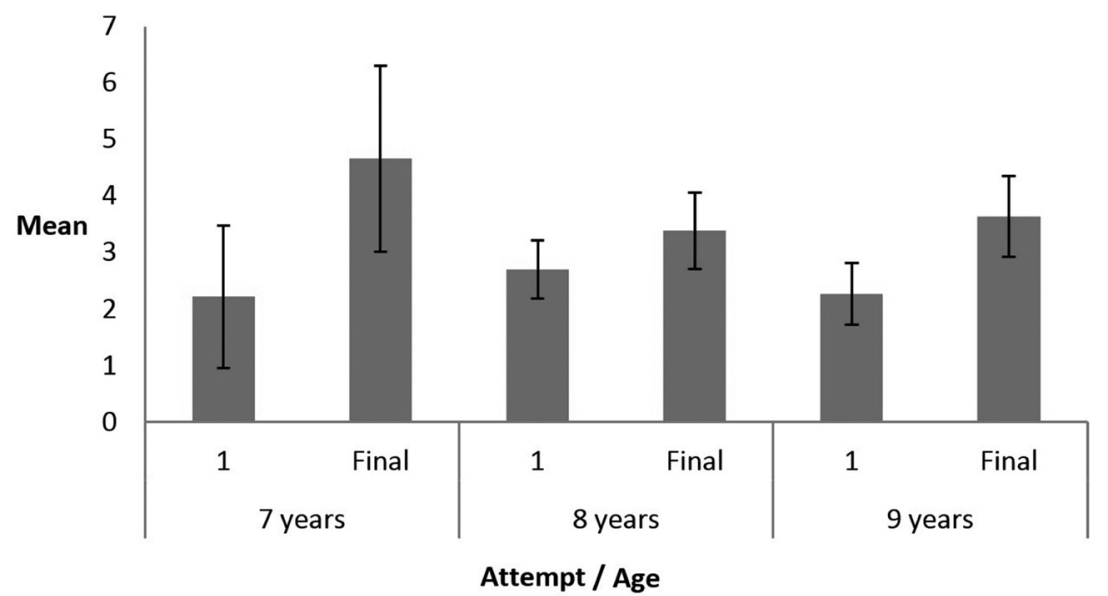

NB. Error bars represent $95 \%$ CI.

Figure 3. Mean performance scores by age on first and final attempt on the game. 
A total of 218 children who played the game and completed a playability questionnaire, which contained three questions. In response to the question "Did you enjoy playing with the game?" $88 \%$ of children responded 'yes'. In response to the question "Would you like to play the game again?" a total of $86 \%$ of the children responded 'yes', and in response to the question "Do you think the game helped you learn about where to cross the road?" a total of $83 \%$ of children responded 'yes'.

\section{Discussion}

The present study aimed to test the utility of an educational road crossing iPad-based game, to provide evidence for the development of this type of resource, which could be rolled-out to UK primary schools. Given that children are overrepresented among pedestrian casualties, finding new and innovative ways of teaching road safety is of the utmost importance. As discussed above, virtual reality could provide a safe, effective and cost-efficient method of teaching road safety (Purcell and Romijn, 2017; Morrongiello, Corbett, Beer and Koutsoulianos, 2018). Many road safety interventions currently used in UK schools are implemented with little to no evidence of effectiveness (Dragutinovic \& Twisk, 2006), it is paramount that future educational interventions are evidenced before implementation.

Overall, the findings from this study suggest that children aged between 7 and 9 years (regardless of gender) were more cautious in their final attempt at the game compared to their first attempt. This suggests that children's road crossing performance improved whilst playing the game, whilst adjusting for increasing complexity of levels. At the same time, it is important to note that this study did not attempt to measure actual road crossing skills, but instead aimed to evaluate whether an iPad-based game could be a useful road safety education tool for primary schools and could engage children in learning about road safety. The results from the brief questionnaire suggests that the majority of children enjoyed playing the game. This is likely in part due to the collaborative approach taken during development of game, which involved consultation with 100 primary school aged children to warrant that the look and feel of the game was suitable for the intended age group. One way that the present study could be extended would be to assess real-world road crossing competence before and after a period of gameplay. The present study has demonstrated that this medium may be an engaging and fun way for children to learn about road safety in an egocentric way, which has previously been demonstrated to be more effective than allocentric methods (Purcell \& Romijn, 2017). 
The development of an iPad-based game may be more practical for a UK wide roll out than the game tested by Morrongiello, Corbett, Beer and Koutsoulianos (2018), since it uses hardware that is frequently available within primary schools in the UK. VR headsets as used by Morrongiello et al. (2018) are less commonly found in primary schools and may be outside of the technology budget of many schools, particularly those in low socioeconomic status areas. The magic portal design used in the game developed for this study allowed the player to be fully immersed in the game whilst holding an iPad up in front of them to look into the virtual world, giving an immersive game playing experience without the need for VR headsets. The wider rollout of this game, free of charge to primary schools across the UK could provide a useful addition to current road safety provision. Adding evidence-based, engaging virtual reality tools such as this one to the current road safety provision in primary schools could be an effective way to reduce road casualty rates among children.

\section{Acknowledgements}

The research reported in this paper was supported by a Road Safety Trust award RST_14_2_16 to the first author. We thank the children and schools who participated in this project and USW for their contribution to the game development used for the purposes of this study.

\section{References}

Arbogast, H., Burke, R. V., Muller, V., Ruiz, P., Knudson, M. M., \& Upperman, J. S. (2014). Randomized controlled trial to evaluate the effectiveness of a video game as a child pedestrian educational tool. Journal of Trauma and Acute Care Surgery, 76(5), 1317-1321.

Assailly, J. P. (2017). Road safety education: What works?. Patient Education and Counseling, 100, S24-S29.

Department for Transport (DfT). (2018). Reported road casualties in Great Britain, annual report. London: Department for Transport

Dragutinovic, N., \& Twisk, D. (2006). The effectiveness of road safety education: A literature review. SWOV Institute for Road Safety Research.

Koopmans, J. M., Friedman, L., Kwon, S., \& Sheehan, K. (2015). Urban crash-related child pedestrian injury incidence and characteristics associated with injury severity. Accident Analysis \& Prevention, 77, 127-136. 
Morrongiello, B. A., Corbett, M., Beer, J., \& Koutsoulianos, S. (2018). A pilot randomized controlled trial testing the effectiveness of a pedestrian training program that teaches children where and how to cross the street safely. Journal of Pediatric Psychology, 43(10), 1147-1159.

Muir, C., O'Hern, S., Oxley, J., Devlin, A., Koppel, S., \& Charlton, J. L. (2017). Parental role in children's road safety experiences. Transportation research part F: Traffic Psychology and Behaviour, 46, 195-204.

Office for National Statistics (2016). Overview of the UK population. Newport: Office for National Statistics.

Purcell, C., \& Romijn, A. R. (2017). Appropriateness of different pedagogical approaches to road safety education for children with developmental coordination disorder (DCD). Research in Developmental Disabilities, 70, 85-93.

Rose, F. D., Attree, E. A., \& Johnson, D. A. (1996). Virtual reality: An assistive technology in neurological rehabilitation. Current Opinion in Neurology, 9(6), 461-467.

Schwebel, D. C., \& McClure, L. A. (2014a). Children's pedestrian route selection: Efficacy of a video and internet training protocol. Transportation research part F: Traffic Psychology and Behaviour, 26, 171-179.

Schwebel, D. C., McClure, L. A., \& Severson, J. (2014b). Usability and feasibility of an internet-based virtual pedestrian environment to teach children to cross streets safely. Virtual Reality, 18(1), 5-11.

Schwebel, D. C., Davis, A. L., \& O’Neal, E. E. (2012). Child pedestrian injury: A review of behavioral risks and preventive strategies. American Journal of Lifestyle Medicine, 6(4), 292-302.

Schwebel, D. C., Gaines, J., \& Severson, J. (2008). Validation of virtual reality as a tool to understand and prevent child pedestrian injury. Accident Analysis \& Prevention, 40(4), 1394-1400.

Van Schagen, I., \& Rothengatter, T. (1997). Classroom instruction versus roadside training in traffic safety education. Journal of Applied Developmental Psychology, 18(2), 283-292.

World Health Organisation (2015). Global status report on road safety. Management of noncommunicable diseases, disability and injury prevention (NVI). Geneva: World Health Organisatiom.

Zeedyk, M. S., Wallace, L., Carcary, B., Jones, K., \& Larter, K. (2001). Children and road safety: Increasing knowledge does not improve behaviour. British Journal of Educational Psychology, 71(4), 573-594. 